\title{
Awareness of Dealing with Multiple Trauma Patients in Madinah, Saudi
} Arabia

\author{
Moayad A. Karbouji ${ }^{1}$, Yousef A. Alrashidi ${ }^{1}$, Mohanad I. Kashkari ${ }^{1}$, Mujahed A. Turjoman ${ }^{1}$, \\ Sultan F. Madani ${ }^{2}$, Fahad A. Almukhlifi ${ }^{2}$ \\ ${ }^{1}$ Orthopedic department, college of medicine, Taibah University, Al-Madinah, Saudi Arabia \\ ${ }^{2}$ College of Medical Rehabilitation Sciences, Taibah University, Al-Madinah, Saudi Arabia \\ Corresponding Author: Moayad A. Karbouji - email: Moayad-A-Karbouji@hotmail.com - mobile: +966562101449
}

ABSTRACT

Background: Motor Vehicle Accidents (MVAs) are major health hazards in Saudi Arabia and may result in multiple injuries. Moreover, it is one of the most common causes of morbidity and mortalities, worldwide. Thus, the awareness of the bystanders who are the first to witness the MVAs is important.

Objective: The purpose of this study was to evaluate of the level of the knowledge among the adults in Al-Madinah in terms of dealing with multiple trauma victims at the scene of the accident.

Methodology: A cross sectional study was conducted in Al-Madinah, Saudi Arabia during October and November 2017 on a university 621 persons participated in the study. A self-administered questionnaire was used. The average age of participants was ranged from 18 to -49 years with male: female ratio of 1.18:1.

Results: Out of 621 participants, $107(17.2 \%)$ exhibited a low level of knowledge, $311(50.1 \%)$ have a good level, and 203 (32.7\%) showed an excellent level. Gender was found to be statistically significant in favor of male participants $(\mathrm{p}=0.004)$. Participants with a high degree of education had been found to have a better knowledge in dealing with trauma patients at the scene of the accident $(\mathrm{p}=0.009)$. Participants who attended a training course showed a better knowledge in dealing in such situations $(\mathrm{p}=0.001)$.

Conclusion: Promoting courses that target educating and training public on the appropriate way of dealing with trauma victims may be helpful.

Keywords: Motor vehicle accidents, multiple trauma patients, First aid, First aid awareness.

\section{INTRODUCTION}

Motor vehicle accidents (MVAs) are a major health hazard and one of the most common causes of multiple traumas ${ }^{(1)}$. Globally, MVAs is the leading cause of all trauma admissions in the hospitals (2). According to The World Health Organization (WHO) report in Feb 2018, MVAs are one of the leading causes of deaths and disabilities to millions of people worldwide which cause economic losses to individuals, families and the nations ${ }^{(3)}$. A significant proportion of MVA victims are aged 15-44 years, which has a major impact on productivity as this is the age-range of the most active population in societies ${ }^{(4)}$. Kingdom of Saudi Arabia (KSA) has a total population of approximately 31 million in $2016^{(5)}$ and it has been estimated that MVAs were the second most common cause of mortality in KSA $(10 \%$ of all deaths in $2016^{(\mathbf{1})}$. over the last decade, the mortalities caused by MVAs in KSA have increased ${ }^{(6)}$. There are several factors that may contribute to the mortality from MVAs in KSA such as significantly severe injuries, and possible deficits in healthcare quality in cases of multiple traumas in addition to limited data on burden of injuries ${ }^{(7)}$. In addition, driving cars in a high speed, not following the road instructions such as seatbelts and poor road conditions were shown to contribute in increasing rate of MVA's ${ }^{(8)}$. At the scene of the accident, first aid delivered by bystanders can save lives and limit the damage until professional help had arrived ${ }^{(9-10)}$. In fact, the first four hours after the accident (i.e. the golden hour) should have the highest concern as victim's lives can be saved during this period if they receive a prompt medical care (11).

\section{METHODOLOGY}

A cross sectional analytical study was conducted in Al Madinah, KSA during the period from October to November 2017, at a university during a campaign about the awareness of first aid. Written informed consent was obtained voluntarily from the participants after explaining the aim and nature of the study. Privacy and confidentiality was 
assured. All participants are citizens of $\mathrm{Al}$ Madinah (Age range of 18-49 years). A random sample of 621 participants was involved (336 males and 285 females). They were given a self-administered questionnaire designed in Arabic language that included demographic questions (age, sex, residence, marital status and educational level) and questions about how to deal properly with the victims in a case as a first aider for multiple trauma victims. The collected data were analyzed using SPSS version 22.0. The ethical approval obtained from the Scientific Research Ethics Committee at Taibah University prior to implementing the study.

\section{RESULTS}

Among the 621 participants, 336 (54.1\%) of them were males, and $285(45.9 \%)$ were females, with male to female ratio of (1.17:1). $97(15.6 \%)$ of the participants had excellent income level, while183 (29.5\%) had good income level. 296 persons $(47.7 \%)$ had average income level, while 45 persons $(7.2 \%)$ had low income level. All the participants live in Al-Madinah city. 442 persons $(71.2 \%)$ were unmarried, while 146 persons (28.8\%) were married. Comparing gender according to the level of awareness by their total right answers, males had a better grade (poor $15.2 \%$ - good $47 \%$ - excellent $37.8 \%$ ), while females had (poor 19.6\% - good 53\% - excellent 26.7\%), Gender has been found to be statistically significant in favor of male participants ( $\mathrm{P}$ value $=0.004)$.

Table (1): Comparing gender by their level of knowledge in terms of dealing with Multiple Trauma patients at the scene of the accident.

\begin{tabular}{|ll|l|l|}
\hline \multirow{2}{*}{ Gender } & & Frequency & Percent \\
\hline male & Low & $\mathbf{5 1}$ & $\mathbf{1 5 . 2}$ \\
\cline { 2 - 4 } & Good & $\mathbf{1 5 8}$ & $\mathbf{4 7 . 0}$ \\
\cline { 2 - 4 } & Excellent & $\mathbf{1 2 7}$ & $\mathbf{3 7 . 8}$ \\
\cline { 2 - 4 } & Total & $\mathbf{3 3 6}$ & $\mathbf{1 0 0 . 0}$ \\
\hline female & Low & $\mathbf{5 6}$ & $\mathbf{1 9 . 6}$ \\
\cline { 2 - 4 } & Good & $\mathbf{1 5 3}$ & $\mathbf{5 3 . 7}$ \\
\cline { 2 - 4 } & Excellent & $\mathbf{7 6}$ & $\mathbf{2 6 . 7}$ \\
\cline { 2 - 4 } & Total & $\mathbf{2 8 5}$ & $\mathbf{1 0 0 . 0}$ \\
\hline P-value & $\mathbf{0 . 0 0 4} *$ & &
\end{tabular}

Table (2): comparing age groups by their level of knowledge in terms of dealing with Multiple Trauma patients at the scene of the accident.

\begin{tabular}{|ll|l|l|}
\hline Categories of age & & Frequency & Percent \\
\hline $\begin{array}{l}\text { less or equal } \\
\text { 25 years old }\end{array}$ & low & $\mathbf{9 0}$ & $\mathbf{2 0 . 2}$ \\
\cline { 2 - 4 } & good & $\mathbf{2 2 7}$ & $\mathbf{5 0 . 9}$ \\
\hline & Excellent & $\mathbf{1 2 9}$ & $\mathbf{2 8 . 9}$ \\
\hline Total & $\mathbf{4 4 6}$ & $\mathbf{1 0 0 . 0}$ \\
\hline $\begin{array}{l}{[26,35]} \\
\text { years old }\end{array}$ & low & $\mathbf{1 5}$ & $\mathbf{1 0 . 3}$ \\
\cline { 2 - 4 } & good & $\mathbf{7 0}$ & $\mathbf{4 7 . 9}$ \\
\hline $\begin{array}{l}{[36,45]} \\
\text { years old }\end{array}$ & Total & $\mathbf{1 4 6}$ & $\mathbf{1 0 0 . 0}$ \\
\hline & low & $\mathbf{2}$ & $\mathbf{9 . 1}$ \\
\hline good & $\mathbf{9}$ & $\mathbf{4 0 . 9}$ \\
\hline $\begin{array}{l}\text { Excellent } \\
\text { 45 years old }\end{array}$ & Total & $\mathbf{2 2}$ & $\mathbf{5 0 . 0}$ \\
\hline & good & $\mathbf{5}$ & $\mathbf{1 0 0 . 0}$ \\
\hline & Excellent & $\mathbf{2}$ & $\mathbf{7 1 . 4}$ \\
\hline Total & $\mathbf{7}$ & $\mathbf{2 8 . 6}$ \\
\hline
\end{tabular}

$446(71.8 \%)$ of the participants were between 18-25 years old and $146(23.5 \%)$ were between 26-35 years old, while 22 (3.5\%) were between $36-45$ years old and $7(1.1 \%)$ were older than 45 years old. Comparing age groups by their total right answers, Participants between 26-35 years old had the best grade (poor 9.1\% - good $40.9 \%$ excellent 50\%), while those who were between 26-35 years old ( poor $20.18 \%$ - good $50.90 \%$ - excellent $28.92 \%$ ) and who were older than 45 years old had no low level at all (low $0 \%$ good $71.4 \%$ - excellent $28.6 \%$ ).

Table (3): comparing educational levels by their level of knowledge in terms of dealing with Multiple Trauma patients at the scene of the accident.

\begin{tabular}{|ll|l|l|}
\hline Educational Level & Frequency & Percent \\
\hline $\begin{array}{l}\text { Elementary } \\
\text { School }\end{array}$ & Excellent & $\mathbf{1}$ & $\mathbf{1 0 0 . 0}$ \\
\hline $\begin{array}{l}\text { Middle } \\
\text { School }\end{array}$ & Low & $\mathbf{5}$ & $\mathbf{3 8 . 5}$ \\
\cline { 2 - 4 } & Good & $\mathbf{6}$ & $\mathbf{4 6 . 2}$ \\
\cline { 2 - 4 } & Excellent & $\mathbf{2}$ & $\mathbf{1 5 . 4}$ \\
\cline { 2 - 4 } & Total & $\mathbf{1 3}$ & $\mathbf{1 0 0 . 0}$ \\
\hline High school & Low & $\mathbf{6 8}$ & $\mathbf{2 0 . 4}$ \\
\cline { 2 - 4 } & Good & $\mathbf{1 6 4}$ & $\mathbf{4 9 . 1}$ \\
\cline { 2 - 4 } & Excellent & $\mathbf{1 0 2}$ & $\mathbf{3 0 . 5}$ \\
\cline { 2 - 4 } & Total & $\mathbf{3 3 4}$ & $\mathbf{1 0 0 . 0}$ \\
\hline University & Low & $\mathbf{3 4}$ & $\mathbf{1 2 . 5}$ \\
\cline { 2 - 4 } & Good & $\mathbf{1 4 1}$ & $\mathbf{5 1 . 6}$ \\
\cline { 2 - 4 } & Excellent & $\mathbf{9 8}$ & $\mathbf{3 5 . 9}$ \\
\cline { 2 - 4 } & Total & $\mathbf{2 7 3}$ & $\mathbf{1 0 0 . 0}$ \\
\hline P-value $=$ & $\mathbf{0 . 0 0 9} *$ & & \\
\hline
\end{tabular}

$273(44 \%)$ had a university as an educational level, while $334(53.8 \%)$ were a high school level. $13(2.1 \%)$ were middle school and only 
$1(0.2 \%)$ had an elementary school level. We noticed from the table that the participants with university level had the best grade (poor $12.5 \%$ - good $51.6 \%$ - excellent $35.9 \%$ ), while with high school level (poor 20.4\% - good $49.1 \%$ - excellent $30.5 \%$ ), then with middle school level (poor 38.5\% - good 46.2\% excellent $15.4 \%$ ), while there was just one participant with elementary school level who has excellent level of knowledge. Participants with a high degree of education have been found to have a better knowledge of how to deal with trauma patients at the scene of the accident $(\mathrm{P}$-value $=0.009)$.

We noticed from the next table(4) that 107 (17.2\%) from the participants had a low level of knowledge in terms of dealing with Multiple Trauma patients at the scene of the accident old, while $311(50.1 \%)$ had a good level, and 203 (32.7\%) had an excellent level.

Table (4): Categories of the level of knowledge of the people of Medina in terms of dealing with Multiple Trauma patients at the scene of the accident.

\begin{tabular}{|l|l|l|l|}
\hline & Frequency & Percent & $\begin{array}{l}\text { Cumulative } \\
\text { Percent }\end{array}$ \\
\hline Low & $\mathbf{1 0 7}$ & $\mathbf{1 7 . 2}$ & $\mathbf{1 7 . 2}$ \\
\hline Good & $\mathbf{3 1 1}$ & $\mathbf{5 0 . 1}$ & $\mathbf{6 7 . 3}$ \\
\hline Excellent & $\mathbf{2 0 3}$ & $\mathbf{3 2 . 7}$ & $\mathbf{1 0 0 . 0}$ \\
\hline Total & $\mathbf{6 2 1}$ & $\mathbf{1 0 0 . 0}$ & \\
\hline
\end{tabular}

For more details about the knowledge levels of the participants, this table showed how they answered the eight questions from the following table, So we noticed that 7 (1.1\%) from them answered only one right answer, while $30(4.8 \%)$ answered two right answers, $70(11.3 \%)$ answered three right answers, 82 $(13.2 \%)$ answered four right answers, 99 $(15.9 \%)$ answered five right answers, 130 (20.9\%) answered six right answers, 134 $(21.6 \%)$ answered seven right answers, and 69 $(11.1 \%)$ answered 8 right answers .

Table (5): The level of knowledge of the people of Medina in terms of dealing with Multiple Trauma patients at the scene of the accident.

\begin{tabular}{|l|l|l|l|}
\hline & Frequency & Percent & $\begin{array}{l}\text { Cumulative } \\
\text { Percent }\end{array}$ \\
\hline low (1/8) & 7 & 1.1 & 1.1 \\
\hline low (2/8) & 30 & 4.8 & 6.0 \\
\hline low (3/8) & 70 & 11.3 & 17.2 \\
\hline good (4/8) & 82 & 13.2 & 30.4 \\
\hline good (5/8) & 99 & 15.9 & 46.4 \\
\hline good (6/8) & 130 & 20.9 & 67.3 \\
\hline $\begin{array}{l}\text { Excellent } \\
(7 / 8)\end{array}$ & 134 & 21.6 & 88.9 \\
\hline $\begin{array}{l}\text { Excellent } \\
(8 / 8)\end{array}$ & 69 & 11.1 & 100.0 \\
\hline Total & 621 & 100.0 & \\
\hline
\end{tabular}

We found 477 (76.8\%) who never attended a training course that were related to dealing with body injuries, while $118(19 \%)$ had attended only once, and $26(4.2 \%)$ had attended more than once. There were 179 (28.8\%) from the participants have watched a demonstration about providing first aids on TV or the internet or any social media, while 442 $(71.2 \%)$ had not watched yet. We noticed from the table below that the participants who attended more than one training course had the best grade (poor $0 \%$ - good $38.5 \%$ - excellent $61.5 \%$ ), and the participants who attended one training course (poor 1.7\% - good $47.5 \%$ excellent $50.8 \%$ ), while those who never attended any training course (poor 22\% - good $51.4 \%$ - excellent 26.6\%). Participants who attended a training course have a better knowledge in dealing with such situations (Pvalue $=0.001$ ).

Table (6): Comparison between persons attended a training course and the level of knowledge in terms of dealing with Multiple Trauma patients at the scene of the accident.

\begin{tabular}{|c|c|c|}
\hline $\begin{array}{l}\text { Have you ever attended } \\
\text { any type of training } \\
\text { courses? }\end{array}$ & Frequency & Percent \\
\hline \multirow{4}{*}{$\begin{array}{l}\text { No: } \\
\text { Good } \\
\text { Excellent } \\
\text { Total }\end{array}$} & 105 & 22.0 \\
\hline & 245 & 51.4 \\
\hline & 127 & 26.6 \\
\hline & 477 & 100.0 \\
\hline \multirow{4}{*}{$\begin{array}{l}\text { Yes (once) : low } \\
\text { Good } \\
\text { Excellent } \\
\text { Total }\end{array}$} & 2 & 1.7 \\
\hline & 56 & 47.5 \\
\hline & 60 & 50.8 \\
\hline & 118 & 100.0 \\
\hline \multicolumn{3}{|l|}{ Yes (more than once): } \\
\hline Good & 10 & 38.5 \\
\hline Excellent & 16 & 61.5 \\
\hline Total & 26 & 100.0 \\
\hline $\mathrm{P}$-value $=$ & \multicolumn{2}{|l|}{$0.000 *$} \\
\hline
\end{tabular}


Table (7): Have you ever attended any type of training courses that are related to dealing with body injuries like First Aid training?

\begin{tabular}{|l|l|l|l|}
\hline & Frequency & Percent & $\begin{array}{l}\text { Cumulative } \\
\text { Percent }\end{array}$ \\
\hline No & $\mathbf{4 7 7}$ & $\mathbf{7 6 . 8}$ & $\mathbf{7 6 . 8}$ \\
\hline $\begin{array}{l}\text { yes } \\
\text { (once) }\end{array}$ & $\mathbf{1 1 8}$ & $\mathbf{1 9 . 0}$ & $\mathbf{9 5 . 8}$ \\
\hline $\begin{array}{l}\text { yes } \\
\text { (more } \\
\text { than } \\
\text { once) }\end{array}$ & $\mathbf{2 6}$ & $\mathbf{4 . 2}$ & $\mathbf{1 0 0 . 0}$ \\
\hline Total & $\mathbf{6 2 1}$ & $\mathbf{1 0 0 . 0}$ & \\
\hline
\end{tabular}

Table (8): Have you ever watched a show about providing first aids on $\mathrm{TV}$ or the internet or any social media site?

\begin{tabular}{|l|l|l|l|}
\hline & Frequency & Percent & $\begin{array}{l}\text { Cumulative } \\
\text { Percent }\end{array}$ \\
\hline Yes & $\mathbf{1 7 9}$ & $\mathbf{2 8 . 8}$ & $\mathbf{2 8 . 8}$ \\
\hline No & $\mathbf{4 4 2}$ & $\mathbf{7 1 . 2}$ & $\mathbf{1 0 0 . 0}$ \\
\hline Total & $\mathbf{6 2 1}$ & $\mathbf{1 0 0 . 0}$ & \\
\hline
\end{tabular}

Table (9): When witnessing a traffic accident, do you think you are capable to help?

\begin{tabular}{|l|l|l|l|}
\hline & Frequency & Percent & $\begin{array}{l}\text { Cumulative } \\
\text { Percent }\end{array}$ \\
\hline $\begin{array}{l}\text { totally } \\
\text { confident }\end{array}$ & $\mathbf{1 2 9}$ & $\mathbf{2 0 . 8}$ & $\mathbf{2 0 . 8}$ \\
\hline $\begin{array}{l}\text { slightly } \\
\text { confident }\end{array}$ & $\mathbf{3 7 2}$ & $\mathbf{5 9 . 9}$ & $\mathbf{8 0 . 7}$ \\
\hline $\begin{array}{l}\text { not } \\
\text { confident }\end{array}$ & $\mathbf{1 2 0}$ & $\mathbf{1 9 . 3}$ & $\mathbf{1 0 0 . 0}$ \\
\hline Total & $\mathbf{6 2 1}$ & $\mathbf{1 0 0 . 0}$ & \\
\hline
\end{tabular}

\section{DISCUSSION}

The awareness of the bystanders who are the first to witness the MVA is very important; Laypeople trained in first aid can reduce delays in seeking medical assistance ${ }^{(12)}$. Although MVAs are a major cause of mortality worldwide few types of research have tried to assess the level of awareness of dealing with multiple trauma patients or any trauma patients. This may possibly be due to the underappreciated role of the lay-first responder. A role, which can help to decrease the mortality rate in multiple trauma injuries (13). In our study, we thought that a good starting point in incorporating the lay-first responder is to evaluate the current level of knowledge that Al-Madinah's population have when it comes to dealing with multiple trauma patients. We found that the majority had a good level of knowledge but there is room for improvement. Other study found statistically significant effects of first aid training on either competence or helping behavior of laypersons (14). Other studies have shown that "first aid education" to public significantly improved the knowledge of lay responders. In other words, laypeople can be trained to provide the first aid in better helping behavior ${ }^{(15)}$. We also tried to determine the factors that influence the level of knowledge, most importantly whether attending a training course would increase their knowledge. In this study, we noticed that the participants who attended more than one training course had the best grade followed the participants who attended one training course and finally those who did not attend any course. Although attending training courses showed a clear improvement in the level of knowledge sadly the percentage of participants that attended these courses was unfortunately low. In this study, we found that the majority of the participants had never attended any type of training courses that are related to dealing with body injuries like first aid courses. Also, the majority had never watched a show about providing first aid on TV or the internet or any social media site. Furthermore, we found that only $20.8 \%$ were totally confident about their capability to help the victims when witnessing a traffic accident. Thus, we recommend providing the population with training courses and possibly making them as one of the requirements for an issuing a driving license.

\section{LIMITATIONS}

Our study showed some limitations, one of them is the absence of a standardized way to truly assess the level of knowledge of the participants in dealing with multiple trauma patients and a crude questioner was used instead. However, the questioner addressed the most important points in dealing with the multiple trauma patients especially the actions, which are doable by the lay-first responder and do not need proper medical training. Another limitation is the fact that our study only assessed the lay-first responder level of knowledge and does not assess wither he can then use this knowledge in a practical setting. However, a level of knowledge is a good starting point especially in the aforementioned important and simple steps that do not need proper medical training. Further research studies are greatly needed to continue in assessing the level of awareness of dealing 
with multiple trauma patients in other populations.

\section{CONCLUSION}

The potential value of first aid training courses for laypersons has assumed a heightened importance in the context of motor vehicle accidents. Thus, promoting courses that target educating and training public on the appropriate way of dealing with trauma victims may be helpful.

\section{REFERENCES}

1. Toroyan T (2009): Global status report on road safety. Injury prevention, 15(4), 286-286.

2. Mansuri F, Al-Zalabani A, Zalat $M$ and Qabshawi R (2015): Road safety and road traffic accidents in Saudi Arabia. A systematic review of existing evidence. Saudi Medical Journal, 36(4): 418-424.

3. Toroyan $\mathbf{T}(\mathbf{2 0 1 5})$ : Global status report on road safety 2015. World Health Organization, retrieved from: http://www.who.int/violence_injury_preventio n/road_safety_status/2015/en/

4. World Health Organization. Injuries, Violence Prevention Department, World Health Organization, World Health Organization. Department of Injuries, \& Violence Prevention (2002): The injury chart book: A graphical overview of the global burden of injuries. World Health Organization. retrieved from:

http://apps.who.int/iris/bitstream/handle/10665 /42566/924156220X.pdf?sequence $=1$

5. General Authority for Statistics (2018): Demographic Research Bulletin. Retrieved

from: https://www.stats.gov.sa/en/4522

6. World Health Organization(2013): Violence, Injury Prevention, Global status report on road safety 2013: supporting a decade of action. World Health Organization. Available at: http://www.who.int/violence_injury_preventio n/road_safety_status/2013/en/

7. Mohammed Y (2018): Trauma care systems in Saudi Arabia: an agenda for action. Annals of Saudi medicine, 30(1), 50.

8. Keay $K$ and Simmonds I (2005): The association of rainfall and other weather variables with road traffic volume in Melbourne, Australia. Accident Analysis \& Prevention, 37(1):109-124.

9. Van de Velde S, Broos P, Van Bouwelen M, De Win R, Sermon A, Verduyckt J, Van Tichelen A, Lauwaert D, Vantroyen B, Tobback C, Van den Steene P (2007): European first aid guidelines. Resuscitation, 72(2):240-251.

10. Handley AJ, Koster R, Monsieurs K, Perkins GD, Davies S, Bossaert L, Bahr J (2006): Erratum to "Section 2: Adult basic life support and use of automated external defibrillators". Resuscitation, 69(2):351.

11. American College of Surgeons (2008): Committee on Trauma. ATLS, advanced trauma life support for doctors: student course manual, available at: https://www.facs.org/quality-

programs/trauma/atls

12. Auf der Heide $E$ (2006): The Importance of Evidence-Based Disaster Planning. Annals of Emergency Medicine, 47(1):34-49.

13. Murad M and Husum H(2010): Trained Lay First Responders Reduce Trauma Mortality: A Controlled Study of Rural Trauma in Iraq. Prehospital and Disaster Medicine, 25(06):.533-539.

14. Van de Velde S, Heselmans A, Roex A, Vandekerckhove $P$, Ramaekers D, Aertgeerts B (2009): Effectiveness of Nonresuscitative First Aid Training in Laypersons: A Systematic Review. Annals of Emergency Medicine, 54(3):447-457.

15. Sangowawa A and Owoaje E (2011): Building capacity of drivers in Nigeria to provide first aid for road crash victims. Injury Prevention,

18(1):62-65. 